\title{
Complete orbital apex syndrome from an onodi cell mucocele: a case report.
}

\author{
Connor Nathe $^{1 *}$, Elizabeth Shen ${ }^{1,2}$, Robert W. Crow ${ }^{1,2}$ \\ ${ }^{1}$ Department of Ophthalmology, University of California, Irvine School of Medicine, Irvine, CA, USA \\ ${ }^{2}$ Gavin Herbert Eye Institute, University of California, Irvine, CA, USA
}

\begin{abstract}
Mucoceles of the posterior ethmoid sinuses are rare, mucous-filled cyst-like lesions that may cause orbital apex syndrome. We present a rare case of complete unilateral orbital apex syndrome in an 86year old woman secondary to an Onodi cell mucocele. She presented with vision loss of the right eye to no light perception as well as complete ophthalmoplegia in that eye. She had significant improvement in vision and complete resolution of ophthalmoplegia following urgent endoscopic surgical decompression. Despite her improvement in vision, mild thinning of the optic nerve was demonstrated on optical coherence imaging of the nerve fiber layer over the next several months, indicating limited yet irreversible damage to the optic nerve. This highlights the need for increased clinical suspicion for orbital apex syndrome due to Onodi cell mucocele and a readiness for prompt surgical intervention.
\end{abstract}

Keywords: Onodi cell, Sphenoethmoidal air cell, Mucocele, Orbital apex syndrome.

Accepted on August 13, 2018

\section{Introduction}

An Onodi cell is defined as pneumatization of the most posterior ethmoid cell both laterally and superiorly into the sphenoid sinus [1]. It is a normal variant of the paranasal sinus and is found in $42 \%-60 \%$ of clinical-anatomical studies [2]. This location is intimately associated with the optic nerve. Mucoceles are dilated mucus filled cyst-like lesions that most likely occur due to inflammation, trauma, scarring or obstruction [3]. Mucoceles of the posterior-most ethmoid sinuses are rare [4], having been reported 23 times since 1998 [3-23], but when they occur, they may cause optic nerve compression resulting in severe visual loss that can become permanent without intervention. Even more rarely, an Onodi cell mucocele may lead to more extensive involvement of the orbital apex resulting in multiple cranial neuropathies seen in orbital apex syndrome. We report a rare case of unilateral orbital apex syndrome due to an Onodi cell mucocele.

\section{Case Report}

An 86-year-old woman with a past ocular history of age-related macular degeneration and bilateral pseudophakia presented with two weeks of progressive vision loss in her right eye. She initially described seeing floaters which progressed to total vision loss. Her family noted decreased movement of her right eye during the period as well. She reported no pain or trauma and denied any prior history of similar vision loss. The patient was examined by a local retina specialist two days prior to presentation and was told that there were no retinal findings to account for her vision loss. On clinical examination, the patient had no light perception (NLP) in the right eye. Visual acuity (VA) in the left eye was 20/50, which was later confirmed to be her baseline visual acuity in both eyes. There was a $4+$ afferent pupillary defect in the right eye. Extraocular motility in the right eye was restricted in all gazes and full in the left eye. Partial right eye ptosis was present. Confrontation visual field was full in the left eye. In both eyes, the patient had no evidence of proptosis, lagophthalmos, lid retraction, or corkscrew vessels on the conjunctiva. Intraocular pressure was 12 in the right eye and 15 in the left. The optic nerve in the right eye had trace edema. There was no optic nerve edema in the left eye. Cup-to-disc ratio was 0.3 in the right eye and 0.5 in the left. Her fundus examination was unremarkable. A computed tomography (CT) scan of the sinuses without contrast demonstrated an opacification of the right lateral sphenoethmoidal (Onodi) air cell in close proximity to the right optic nerve (Figure 1). An MRI of the head and orbit with and without contrast (Figure 2) demonstrated an opacified right sphenoethmoidal air cell, which extended to the anterior clinoid process in close proximity to the optic nerve. There was no subjacent edema or adjacent bony erosion. The parenchyma showed no acute infarct, hemorrhage, mass effect or midline shift. The optic nerves, optic chiasm and optic tracts appeared normal. There was no intraconal or extraconal mass identified. Extraocular muscles and globes appeared normal. The patient was diagnosed with orbital apex syndrome with involvement of cranial nerves two, three, four, and six, secondary to an Onodi cell mucocele. The next day, the patient underwent right endoscopic sinus surgery with optic nerve decompression. The sinus was found to be purulent with gram stain negative mixed growth. The patient was treated with oral amoxicillin / clavulanic acid and prednisone. On post-operative day one her VA had improved to hand motion and she had improved ocular motility in left gaze. At post-operative week one her VA was 20/200 with improvement of extraocular movements in all gazes. On fundus exam, optic nerve edema had resolved but new optic disc pallor was observed. Optical coherence tomography (OCT) of the nerve fiber layer in the right eye was performed and revealed an average nerve fiber layer thickness 
Citation: Connor N,Elizabeth S,Robert WC. Complete orbital apex syndrome from an onodi cell mucocele: a case report. J Clin Ophthalmol. 2018;2(2):63-66.

of $105 \mu \mathrm{m}$ (Figure 3A); Humphrey Visual Field (HVF) 24-2 testing demonstrated a significantly constricted visual field in the right eye (Figure 4A). OCT of the nerve fiber layer in the left eye revealed an average nerve fiber layer thickness of 111 $\mathrm{m}$ (not shown) that remained stable throughout the course of follow up. By post-operative month one VA improved to 20/50, and the patient had recovered full extraocular movements; repeat OCT imaging demonstrated an average nerve fiber layer thickness of $97 \mu \mathrm{m}$ (Figure 3B). HVF 24-2 testing at post-operative month four revealed significant improvement in visual field (Figure 4B). Retinal nerve fiber thinning progressed on OCT at post-operative months four and nine (Figure 3C, D). This progression represents normal evolution after optic nerve injury.

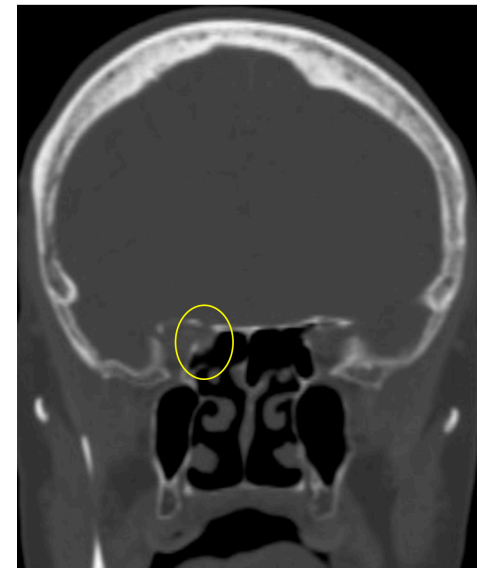

Figure 1: Right opacified Onodi cell on coronal CT of the sinuses.

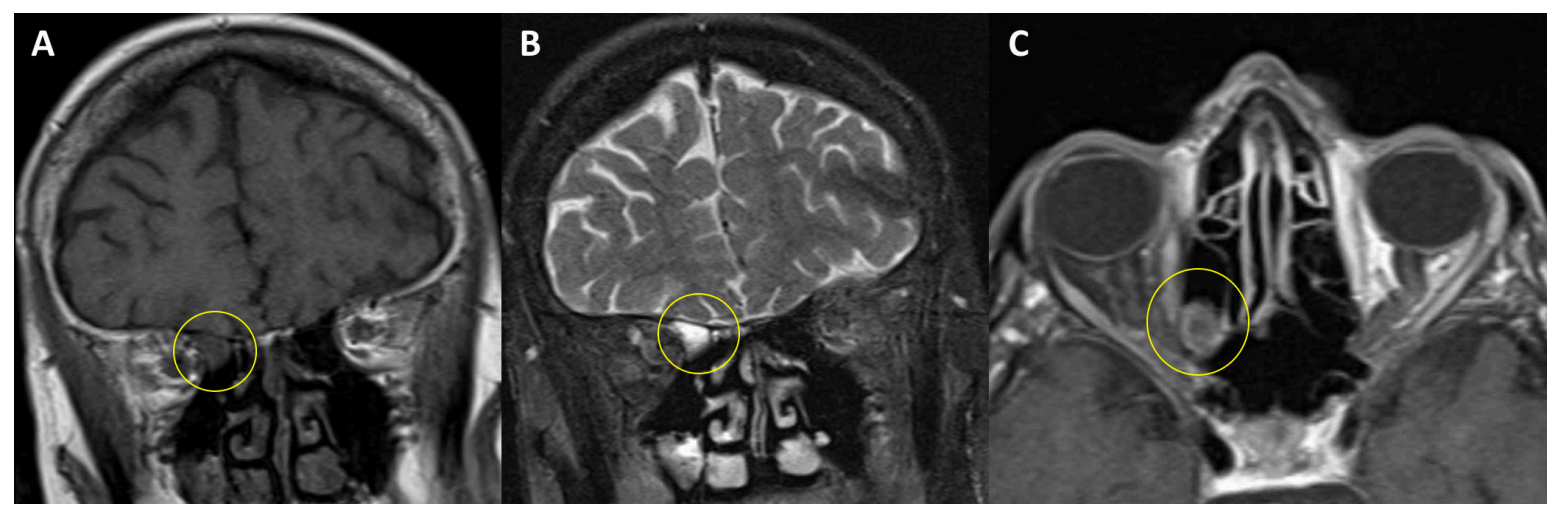

Figure 2: Right opacified Onodi cell magnetic resonance imaging of the sinuses. (A) Coronal T1-weighted view. (B) Coronal T2-weighted view. (C) Axial T1-weighted post-contrast view. Yellow circle indicates site of lesion.

A
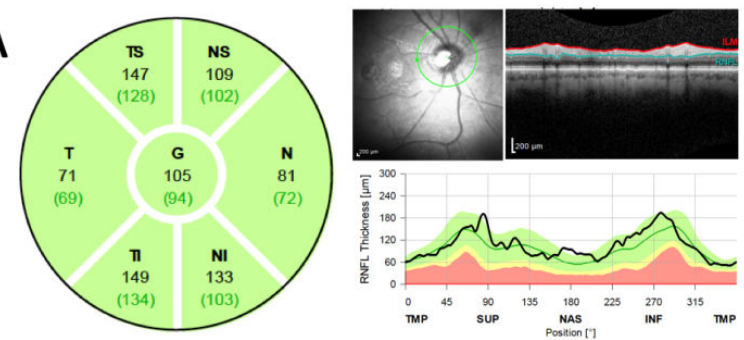

C
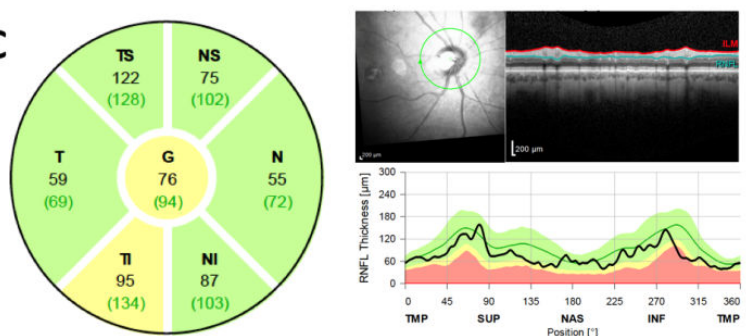

B

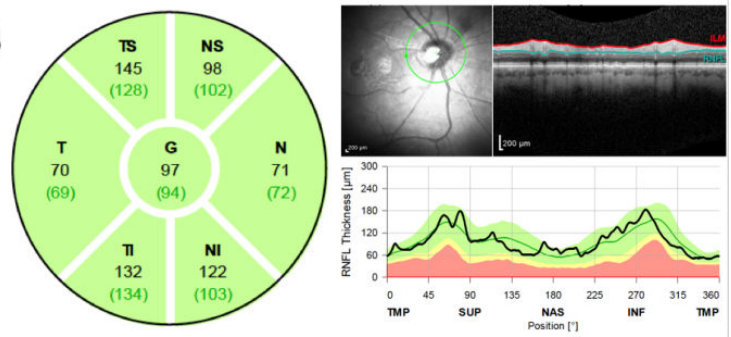

D

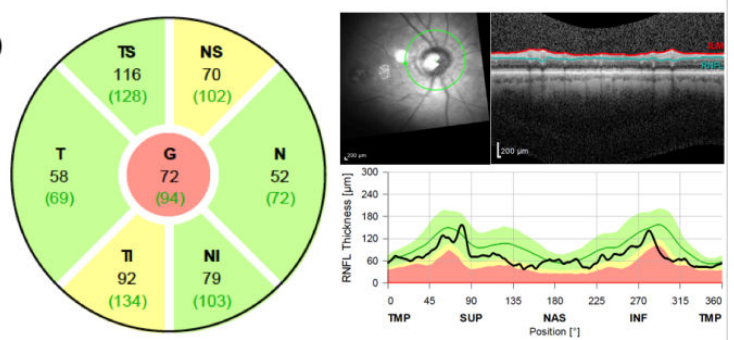

Figure 3: Optical coherence tomography of the right eye nerve fiber layer at A) post-operative week 1, B) post-operative month 1, C) postoperative month 4, and D) post-operative month 9. 
A

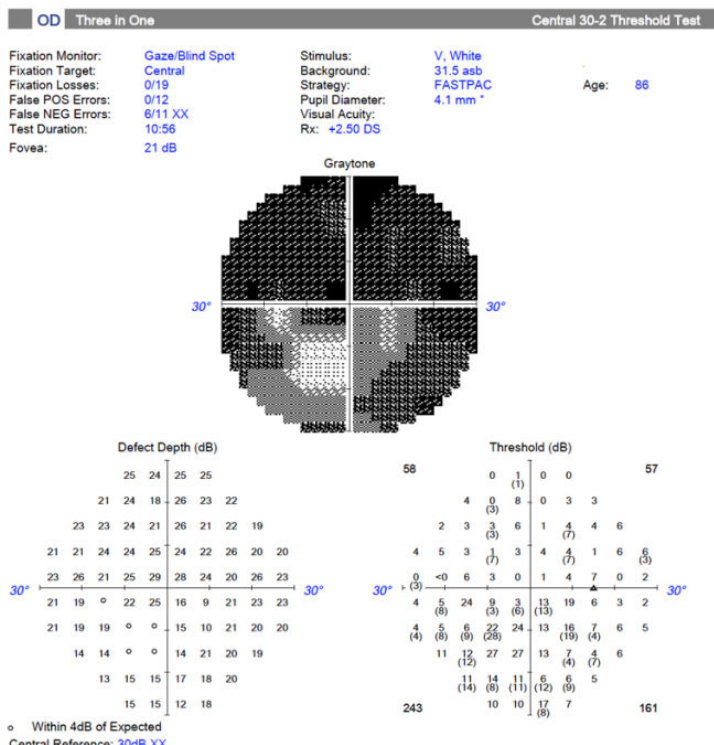

B

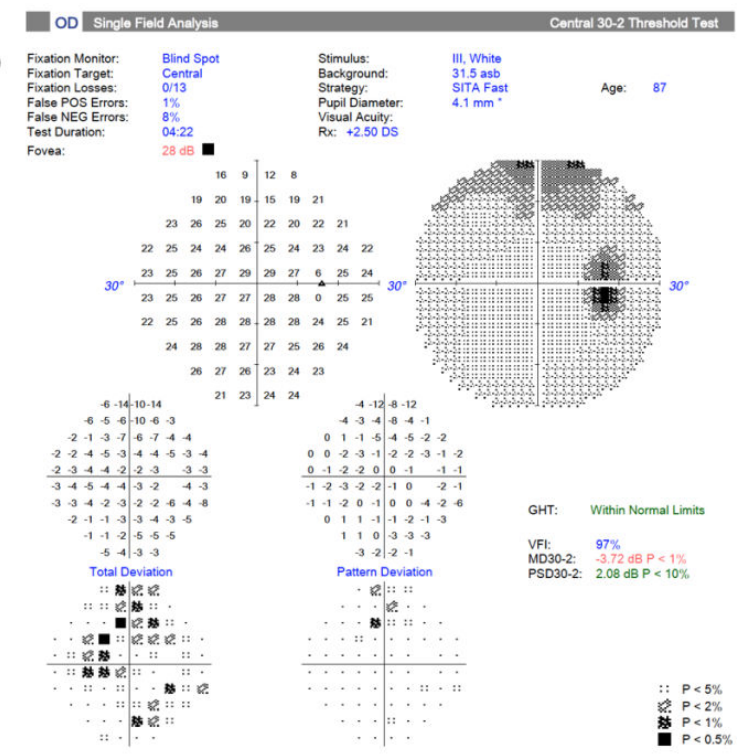

Figure 4: Humphrey Visual Field in right eye at A) post-operative week 1 and B) post-operative month 4.

\section{Discussion}

Onodi cells were once believed to occur in $8 \%-14 \%$ of the population [5], but a more recent study found the prevalence to be much greater, at $52.7 \%$ [6]. Additionally, mucoceles of Onodi cells are underreported, as patients with posterior paranasal sinus mucoceles often do not present with rhinologic problems and may be completely asymptomatic [25]. Cases often require CT or MRI imaging for diagnosis and despite the increased soft tissue detail expected with MRI, the variable hydration of mucus in these cyst-like structures has made consistent identification relatively difficult until recently [26-27]. Even in Japan, where posterior ethmoid and sphenoid sinus mucoceles are less rare, $78 \%$ of cases are diagnosed postoperatively [25]. Our review of the literature identified 23 cases of Onodi cell mucocele reported since 1998 and, although many presented with ophthalmologic symptomatology, only three (13\%) of the cases involved orbital apex syndrome [3-23]. To our knowledge, this case is the fourth reported case of orbital apex syndrome from an Onodi cell mucocele and the first to demonstrate long-term changes in nerve fiber layer thickness based on OCT imaging of the nerve.

The optic nerve can be affected by paranasal sinus mucoceles as a result of either ischemic injury due to mechanical compression or by direct extension of the inflammatory process. Our patient demonstrated a two-week progressive visual loss, which suggests a compressive mechanism rather than the more rapid visual loss seen with direct spread of infection or inflammation [24]. The lack of enhancement at the orbital apex on post-contrast T1 MRI (Figure 2C) supports the absence of a prominent infectious etiology for the patient's symptoms, despite the purulence found in the Onodi cell during decompressive surgery.

Our patient fortunately experienced significant improvement in vision and resolution of ophthalmoplegia following endoscopic surgical decompression, despite complete loss of vision to NLP and the two-week interval before obtaining a definitive diagnosis and treatment. Although vision improved, the mild thinning of the optic nerve over time demonstrated on OCT imaging indicates that limited but irreversible ischemic damage was done due to compression. Progression of the OCT between immediately post-op and 1 month later is due to axonal degeneration taking time to manifest as a structural change upstream from the site of injury. Animal studies have shown retinal ganglion cell (RGC) death to occur over as much as two weeks following optic nerve crush injuries [28] with a further delay of approximately 3 days between RGC death and RGC clearance [29].

Zukin et al. [3] showed that time to surgery after symptoms onset exhibits an inverse correlation with visual improvement. Prompt surgical intervention is important in these cases. As our imaging techniques improve and allow for more successful identification of this uncommon but potentially catastrophic lesion, recognition of paranasal sinus anatomical variants and increased clinical suspicion of orbital apex syndrome due to Onodi cell mucocele is important.

\section{References}

1. Stammberger HR, Kennedy DW. Paranasal sinuses: Anatomic terminology and nomenclature. Ann Otol Rhinol Laryngol (Suppl).1995;167:7-16.

2. Meybodi AT, Vigo V, Benet A. The Onodi Cell: An Anatomic Illustration. World Neurosurg. 2017;103:950.e5e6.

3. Zukin LM, Hink EM, Liao $\mathrm{S}$, et al. Endoscopic Management of Paranasal Sinus Mucoceles: Meta-analysis of Visual Outcomes. Otolaryngology-Head and Neck Surgery. 2017;57(5):760-6.

4. Lee JM, $\mathrm{Au} \mathrm{M}$. Onodi cell mucocele: case report and review of the literature. Ear Nose Throat J. 2016;95(9):E4-8. 
Citation: Connor N,Elizabeth S,Robert WC. Complete orbital apex syndrome from an onodi cell mucocele: a case report. J Clin Ophthalmol. 2018;2(2):63-66.

5. Yoon KC, Park YG, Kim HD, et al. Optic neuropathy caused by a mucocele in an Onodi cell [letter]. Jpn J Opthalmol. 2006;50(3):296-8.

6. Senturk M, Guler I, Azgin I, et al. The role of Onodi cells in sphenoiditis: results of multiplanar reconstruction of computed tomography scanning. Braz J Otorhinolaryngol. 2017;83(1):88-93.

7. Ogata Y, Okinaka Y, Takahashi M. Isolated mucocele in an Onodi cell. ORL J Otorhinolaryngol Relat Spec. 1998;60(6):349-52.

8. Klink T, Pahnke J, Hoppe F, et al. Acute visual loss by an Onodi cell. Br J Opthalmol. 2000;84(7):801-2.

9. Kumagai M, Hashimoto S, Suzuki H. Orbital apex syndrome caused by sphenoethmoid mucocele. Auris Nasus Larynx 2003;30(2):295-7.

10. Kitagawa K, Hayasaka S, Shimizu K, Nagaki Y, Optic neuropathy produced produced by a compressed mucocele in an Onodi cell. AM J Opthalmol 2003;135(2):253-4.

11. Yoshida K, Wataya T, Yamagata S. Mucocele in an Onodi cell responsible for acute optic neuropathy, BR J Neuroserg. 2005;19(1):55-6.

12. Fukuda Y, Chikamatsu K, Ninomiya H, et al. Mucocele in an Onodi cell with simultaneous bilateral visual disturbance. Auris Nasus Larynx. 2006;33(2):199-202.

13. Nonaka M, Fukumoto A, Nonaka R, et al. A case of mucocele in an Onodi cell. J Nippon Med Sch. 2007;74(4):325-8.

14. Toh ST, Lee JC. Onodi cell mucocele: Rare case of optic compressive neuropathy. Arch Otolaryngol Head Neck Surg. 2007;133(11):1153-6.

15. Lim SA, Sitoh YY, Lim TC, et al. Clinics in diagnostic imaging (120). Right rhinogenic optic neuritis secondary to mucocele of the Onodi cell. Singapore Med J. 2008;49(1):84-7

16. Chee E, Looi A. Onodi sinusitis presenting with orbital apex syndrome. Orbit. 2009;28(6):422-4.

17. Wu W, Sun MT, Cannon PS, et al. Recovery of visual function in a patient with an Onodi cell mucocele compressive optic neuropathy who had a 5-week interval between onset and surgical intervention: A case report. J Opthalmol. 2010;2010:483056.

18. Fukuda H, Fukumitsu R, Andoh M, et al. Small Onodi cell mucocele causing chronic optic neuropathy: Case report. Neurol Med Chir (Tokyo). 2010;50(10):953-5.

19. Victores A, Foroozan R, Takashima M. Recurrent Onodi cell mucocele: Rare case of 2 different ophthalmic complications. Otolaryngol Head Neck Surg. 2011;146(2): 338-9.

20. Nickerson JP, Lane AP, Subramanian PS, et al. Onodi cell mucocele causing acute vision loss: Radiological and surgical correlation. Clin Neuroradiol. 2011;21(4):245-8.

21. Cheon YI, Hong SL, Roh HJ, et al. Fungal ball with Onodi cell mucocele causing visual loss. J Craniofac Surg. 2014;24(2):512-4.

22. Fleissig E, Spierer O, Koren I, et al. Blinding orbital apex syndrome due to Onodi cell mucocele. Case Rep Opthalmol Med. 2014;2014:453789.

23. Rimmer J, Beale T, Lund VJ. Visual loss in patients with sphenoethmoidal cells. J Laryngol Otol. 2015;129(2): 198-201.

24. Moriyama H, Nakajima T, Honda Y. Studies on mucocoeles of the ethmoid and sphenoid sinuses: analysis of 47 cases. J Laryngol Otol. 1992;106(1):23-7.

25. Tseng CC, Ho CY, Kao SC. Ophthalmic manifestations of paranasal sinus mucoceles. J Chin Med Assoc. 2005;68(6): 260-4.

26. Lim CC, Dillon WP, McDermott MW. Mucocele involving the anterior clinoid process: MR and CT findings. AJNR Am J Neuroradiol. 1999;20(2):287-90.

27. Toriumi DM, Sykes JM, Russell EJ, et al. Sphenoethmoid mucocele with intracranial extension: radiologic diagnosis. Otolaryngology-Head and Neck Surgery. 1988;98(3): 254-7.

28. Nadal-Nicolás FM, Jiménez-López M, Sobrado-Calvo P, et al. Brn3a as a marker of retinal ganglion cells: qualitative and quantitative time course studies in naive and optic nerve-injured retinas. Invest Ophthalmol Vis Sci.2009;50(8):3860-8.

29. Nadal-Nicolás FM, Jiménez-López M, Salinas-Navarro M, et al. Microglial dynamics after axotomy-induced retinal ganglion cell death. J Neuroinflammation. 2017;14(1):218.

\section{*Correspondence to}

Connor Nathe

Department of Ophthalmology

University of California

850 Health Sciences Road, Irvine, CA 92697

Tel: (949) 824-2020

E-mail: cnathe@uci.edu 